\title{
Epigenetics mechanisms and degenerative diseases
}

\author{
Kalpana Joshi $^{{ }^{*}}$, Smitha Bhat ${ }^{2}$, Pooja Deshpande ${ }^{3}$, Mayura Sule ${ }^{3}$, Kapaettu Satyamoorthy ${ }^{2}$ \\ ${ }^{1}$ School of Biomedical Sciences, Symbiosis International University, Pune, India \\ ${ }^{2}$ Manipal Life Sciences Centre, Planetarium Complex, Manipal University, Manipal, India \\ ${ }^{3}$ Sinhgad Institute, Pune, India \\ Email: joshikalpana@gmail.com
}

Received 12 July 2012; revised 12 August 2012; accepted 15 September 2012

\begin{abstract}
Epigenetic regulations are heritable changes in gene expression that occur in the absence of alterations in DNA sequences. Various epigenetic mechanisms include histone modifications and DNA methylations. In this review, we examine methods to study DNA methylations and their contribution to degenerative diseases by mediating the complex gene-by-environment interactions. Such epigenetic modifications despite being heritable and stably maintained are also potentially reversible and there is scope for the development of epigenetic therapies for this disease.
\end{abstract}

Keywords: Epigenetics; DNA Methylation; Histone Modifications; DNA Methylation; Rheumatoid Arthritis

\section{INTRODUCTION}

With the phenomenal success of human genome project, sequences for approximately 25,000 genes have been identified. Most of identified genes have yet to be functionally characterized. Many of these genes might contribute to physiological processes and, or pathogenesis revealing the mystery behind the etiology of disease [1]. Phenotypic alterations irrespective of identical DNA sequence gave impetus to understand the mechanisms involved in such alterations which were result of nonmendelian and incongruent patterns of inheritance in organisms [2]. Epigenetics thus involves the mechanisms which establish and transmit different patterns of gene expression within all types of cells irrespective of identical DNA sequence. Epigenetic silencing of some genes serves as control mechanism during differentiation of cells. These modifications are prone to changes throughout life [3]. The major epigenetic alterations that have been identified are DNA methylation, histone modifications and splicing of messenger RNA [microRNA or siRNA].

"Corresponding author.

\section{EPIGENETIC MECHANISMS}

\subsection{DNA Methylation}

DNA methylation occurs in both prokaryotes as well as eukaryotes. In prokaryotes it occurs on cytosine and adenosine, while in eukaryotes it occurs on cytosine [4]. In mammalian cells DNA is methylated at 5 th position of cytosine ring. DNA methylation in mammals is required for silencing of transposable elements, allele specific expression of imprinted genes, $\mathrm{X}$ chromosome inactivation in females [5]. There are two mechanisms by gene repression is achieved, first modification of cytosine inhibits binding of DNA binding factors to specific DNA sequence and second methyl $\mathrm{CpG}$ binding proteins through transcriptional corepressors inhibit gene expression [1]. DNA methyltranferases target the dinucleotide palindrome $\mathrm{CpG}$ islands and $60 \%$ of genes contain $\mathrm{CpG}$ islands in the promoter region. DNA methyltransferase can be classified into two classes one which is responsible for methylation and other for maintenance. Evidence suggests that DNMT3a and DNMT3b DNA methyltranferases are responsible for de novo methylation. While DNMT1 is associated maintenance of DNA methylation pattern during DNA replication [6].

The exact mechanisms of de novo DNA methylation are still being elucidated. Recent studies have emphasized the importance of PWWP domain in humans, as mutation in this domain reduces DNA methylation of classical satellite 2 DNA in Immunodeficiency, Centromeric instability and Facial anomalies [ICF] syndrome which is a rare autosomal recessive disease [7]. The second mechanism is interaction of DNMTs with transcriptional repressor protein which can result into efficient repression of the target gene [8]. Tissue specific methylation patterns can be established but it would require de novo methylation as well as demethylation. Although till now there is no confirmed characterized DNA demethylases, several mechanisms are proposed for active DNA demethylation. Recent study by Kangaspeska et al. and Metivier et al. has proposed that DNA methytransferases [DNMT3a and DNMT$3 b]$ are responsible for demethylation [9-11]. 


\subsection{Histone Modification}

The eukaryotic genomic DNA is packed with histone proteins into chromatin causing DNA condensation. Condensation of DNA causes an obstacle to nuclear processes such as replication, transcription and repair, whereas decondensation facilitates the nuclear processes. Histone, the basic repeating unit of chromatin in nucleosome, is an octamer of four core histones H2A, H2B, H3 and $\mathrm{H} 4$ and 146 base pairs of DNA wrapped around the histone [12]. Histone modifications mostly occur in a combinational manner and are correlated with either activating or repressing the gene function.

\section{- Histone Acetylation}

Acetylation and deacetylation of histones gives rise to transcriptionally active chromatin and inactive chromatin respectively. Modifications mostly occur at amino terminal amino acids positions 9, 14, 18, 23 of $\mathrm{H} 3$ lysine and 5, 8, 12, 16 of H4 lysine [13]. Acetylation causes the neutralization of basic charge of histone tails reducing its affinity for DNA, adjacent histone within the nucleosome and also with other regulatory proteins and leading to the formation of open accessible form of DNA that will aid in transcription activity [14]. Histone acetylation and deacetylation are carried out by chromatin associated enzymatic systems which reside in multisubunit complexes and catalyze the incorporation or removal of covalent modifications from histone targets. Histone acetyl transferases [HATs] complexes are composed of proteins with homology to transcriptional regulators possessing HAT activity [14]. Histone deacetylases act as corepressors of transcription. Inhibition of HDACs activity and inactivation of sites for hypoacetylation in histone $\mathrm{H} 4$ are known to disrupt the formation of highly condensed heterochromatin regions leading to hindrance in the transcription activity [15]. The deacetylation of lysine 16 of $\mathrm{H} 4$ is an important event in the disruption of heterochromatin regions.

\section{- Histone phosphorylation}

Another modification that histone undergoes is phosphorylation at the serine 10 of histone $\mathrm{H} 3$ causing gene activation of mammalian cells [16]. The addition of negatively charged phosphate groups to histone tails neutralizes their basic charge and is thought to reduce their affinity for DNA. Phosphorylation may contribute to transcriptional activation through the stimulation of HAT activity on the same histone tail. DNA damage signalling pathways activates phosphorylation of histone $\mathrm{H} 3$ causing alteration of chromatin structure facilitating repair $[17,18]$.

\section{- Histone methylation}

Histone methylation is generally associated with transcriptional repression. Methylation occurs at lysine residues H3 [4] and H4 [19] modifying them to mono-, di-, trimethylated. The tri-methylated states in $\mathrm{H} 3$ and $\mathrm{H} 4$ amino terminal can be stably propagated during cell division [20]. There are two classes of methylating enzymes, PRMTs [protein argentine methyl transferases] and HKMTs [histone lysine methyl transferases] [19,21]. Methylated lysine residues are considered to be chemically more stable. Lysine specific demethylases act on the mono- and distates and are associated with large protein repressive complexes which also contain HDACs [22]. Hydroxylases and dioxygenases another class of histone demethylases which act via radial attack [23].

\subsection{MicroRNA}

Mammalian cells harbour numerous small non-protein coding RNA's, including snoRNAs, miRNAs, and siRNAs [small nucleolar RNA's, microRNA's and short interfering RNA's] which regulate gene expression at many levels. miRNA appear to regulate the events through the lifecycle, including embryonic and post embryonic stages suggesting their important and diverse role in development of an organism. Consistent with a diverse role of miRNAs in development, a variety of miRNAs exhibit temporal and tissue specific expression patterns [24]. miRNA causes rapid transitions in gene expression. The targets are often transcription factors that regulate cell differentiation enabling the cell to respond quickly to developmental decisions. miRNA are formed by dicer cleavage of hairpin loop RNA precursors [25]. These precursors are transcribed from genes within the genome. The number of miRNA genes in humans is around $200-$ 255 corresponding to $0.5 \%-1 \%$ of the total genes in genome.

siRNA are incorporated into RNA induced silencing complex [RISC] composed of numerous proteins leading to unwinding of the duplex to single stranded siRNA's which remains associated with RISC preferably to strands whose 5'ends base pair more weakly to their complements. The retained RNA strand acts as a guide for RISC to find mRNA transcripts with complementary sequence. If such mRNA molecules are found, the base paring interactions between siRNA and mRNA lead to transcript cleavage and degradation. siRNA may also guide factors that methylate histones and DNA resulting in transcriptional silencing [26] siRNA, miRNA repress gene expression by negatively regulating complementary mRNA.

Concept of epigenetics revolves around the role of environmental factors in concurrence with genetic predisposition of the disease. From the past evidences understanding regulation of genes at transcriptional level and underlying epigenetic mechanism has emerged as newer approach in defining the pathways of disease and identifying the newer drug targets. This review focuses on methods for the Genome-Wide analysis of DNA Methylation levels and patterns and epigenetic mechanisms that un- 
derpin the complexity of pathogenesis of complex disease like rheumatoid arthritis, asthma, obesity, Alzheimer.

\section{OVERVIEW OF DIFFERENT DNA METHYLATION ANALYSIS TECHNIQUES}

DNA methylation is an essential epigenetic modification in the DNA of human genome. Aberrant DNA methylation has been shown to be associated with a variety of diseased condition. A wide range of methods have been developed and has revolutionized our understanding of DNA methylation and also provided us a new insight into the biological role of this epigenetic mark. In this write-up, methods have been broadly classified into three types - genome wide analysis, global methylation analysis and gene-specific methylation analysis.

\subsection{Genome Wide Analysis of DNA Methylation}

Restriction Landmark Genomic Scanning for screening of methylated sites [RLGS] is a method which makes use of restriction enzymes recognition site as landmarks for the analysis of the genome. This method has many advantages and they are 1) high-speed simultaneous scanning of thousands of restriction landmarks; 2) its requires no hybridization procedure and genome of any organism can be analyzed because of direct-labelling of restriction enzyme sites and 3) one can detect and differentiate the haploid and diploid genomic DNA by looking into the spot intensity of copy number of restriction landmark. The profiles generated are highly reproducible and enables direct comparison of genomic DNA between two individuals or between two tissues, e.g. normal and tumor tissue [27]. In amplification of intermethylated sites [AIMS] method, DNA is digested using the methylation sensitive restriction enzyme. Digested fragments are ligated and PCR amplified. The amplified product is run on the high resolution denaturation gel for the separation [28]. Differential Methylation Hybridization $[\mathrm{DMH}]$ enables us to discriminate between the methylation profiles of two samples; test and control DNA cohybridized to an array of immobilized $\mathrm{CpG}$ islands [29]. All these [RLGS, AIMS, DMH] methods have been shown to be useful for methylome profiling. However, the need of DNA sequencing in the case of both RLGS and AIMS to determine the sequence identity of differential spots or bands has been a practical limitation of these two methods. A modification in the DMH method is the use of the methylation dependent endonuclease McrBC [30]. McrBC only cleaves methylated DNA [5 mC, 5 hmC, or N4-methylcytosine] and shows no activity toward unmethylated DNA. When compared to other methylation-sensitive enzyme, McrBC provides greater sensitivity for the densly methylated region. A further modified method is the MethylaScope [31,32] where sheared DNA is taken instead of the Mse I digested DNA. Another method is Hpa II tiny fragment enrichment by ligation mediated PCR [HELP] [33,34], here Hpa II or Msp I fragments are amplified using ligation-mediated PCR followed by array hybridization or next generation sequencing. Another modification of the DMH is microarray-based methylation assessment of single samples [MMASS] [35]. It is an optimized microarray method to identify the genome-wide methylated $\mathrm{CpG}$ island and directly compares the methylated sequence with the unmethylated the sample [36,37]. Recently immunoprecipitation based methods have been developed that makes use of $5 \mathrm{mC}$ marks and the proteins that selectively bind $5 \mathrm{mC}$ such as MeCP2 and MBD2; can be detected using specific antibodies [38]. Methylated DNA immunoprecipitation $[39,40]$ [MeDIP or $\mathrm{mDIP}]$ is a genome wide technique and involves isolating the methylated DNA fragments by raising antibody specific to the 5-methylcytosine and the purified fraction of the methylated DNA can be used for the high throughput DNA detection methods such as DNA microarray [MeDIPchip] or next generation sequencing [MeDIP-seq]. Another method is the methylated-CpG island recovery assay [MIRA]; this method makes use of the high affinity antibody to MBD2b/MBD3L1 complex binding to the double-stranded CpG-methylated DNA. Though affinitybased methods allow for rapid and efficient genomewide assessment of DNA methylation, they do not yield information on individual $\mathrm{CpG}$ dinucleotides and require substantial experimental or bioinformatics adjustment for varying $\mathrm{CpG}$ density at different regions of the genome [41]. Another recent addition is sequencing of bisulphite-treated chromatin immunoprecipitated DNA [BisChiPseq], where one can quantitatively assess the association of DNA methylation pattern with chromatin modification [42]. Methods like MeDIP, HELP, McrBC provide useful information, but show significant limitations such as MeDIP shows bias for the $\mathrm{CpG}$ islands while HELP shows relative incomplete coverage and location imprecision in McrBC. To meet these limitations tiling array design and data processing was optimized that resulted in improved performance for McrBC digestion-based techniques. This optimized workflow is referred to as comprehensive high-throughput arrays for relative methylation (CHARM) [43]. Methylation sensitiveamplified fragment length polymorphism (Ms-AFLP) is a method that makes use of enzymes such as Not I, Hpa II and Msp I, that are differentially sensitive to methylated cytosine for the genome wide analysis of DNA methylation. Modifications in this method includes FL-MS-AFLP analysis where, FITC tagged primers specific for the restriction enzyme specific adaptors and 
fluorescent PCR products are analyzed using automated sequencer. This analysis enables detection as well as quantitation of the $350 \mathrm{CpG}$ loci in a PCR run [44]. LUMA [LUminometric Methylation Assay], a novel pyrosequencing based method for the estimation of genome wide DNA methylation level. This method is highly quantitative, reproducible and does not involve bisulfite conversion step. It requires about 200 - $500 \mathrm{ng}$ of DNA and the total assay time is about $6 \mathrm{~h} \mathrm{[45].} \mathrm{Micro-}$ array based integrated analysis of methylation by isoschizomer [MIAMI] [46] method uses restriction enzymes that are isoschizomer for the detection of DNA methylation. A recently reported method for precise DNA methylation levels involves initial enzymatic hydrolysis of the DNA. The resulting mononucleotide is then coupled with BODIPY FL EDA: N-[3-[4,4-difluoro-5,7-dimethyl-4bora-3a,4a-diaza-s-indacen-3-yl]propionyl]ethylenediamine hydrochloride which is followed by micellar electrokinetic chromatography $[\mathrm{MEKC}]$ combined with laserinduced fluorescence [LIF] detection [47].

\subsection{Global DNA Methylation Analysis}

Global DNA methylation has been proposed as a molecular marker for biological processes such as cancer [48]. A variety of methods are currently available to investigate global DNA methylation, including HPLC [49], capillary electrophoresis [50], and a combination of LC and MS [51]. In HPLC based methods, the level of DNA methylation is usually obtained by chromatographic separation of the individual nucleotide bases or their related deoxyribonucleotides or deoxyribonucleosides, and quantification of the $5 \mathrm{mC}$ after separation. The advantage of this method is that the deoxyribonucleotides can be easily distinguished from the ribonucleotide contaminants and thus avoids the error due to RNA and the technique is suitable for measuring the $5 \mathrm{mdCMP}$ content in $1 \mu \mathrm{g}$ or more of DNA. Recently it was shown that methylated cytosine can be accurately and reproducibly measured in as little as $3 \mu \mathrm{g}$ of DNA using this HPLC [52]. Recently, Kurita R et al. 2012 [53] have developed a method for quantitative measurement of DNA methylation levels using enzyme linked immunosorbent assay [ELISA] with electrochemiluminescence [ECL] detection. Using this method authors quantitatively measured methyl-cytosine and it was in $1-100$ pmol range. This method is highly sensitive for real DNA methylation measurements and does not require PCR amplification and is also highly selective for methylcytosine. Another simple colorimetric method was reported by Ge C et al. 2012 [54], where Adenomatous polyposis coli [APC] gene with small $\mathrm{CpG}$ region having methylated cytosine was synthesised and tested. Using anti-methylcytosine magnetic microspheres [MMP] methylated APC was captured and enriched. Probes partly complementary to methylated APC region was added which leads to the formation of DNA duplexes. The probes were separated by heat denaturation in unmodified gold nanoparticle [AuNP] solution and using salt-induced aggregation, colorimetric detection was performed. Sensitivity of this method is upto $80 \mathrm{fmol}$ and is a simple, semiquantitave method and rapid tool for DNA methylation detection.

\subsection{Gene-Specific Methylation Analysis}

For the investigation of DNA methylation patterns in single genes or target sites the usual method of choice is bisulphate conversion followed by DNA sequencing. When DNA treated with sodium bisulfite, under the treatment conditions, leads to the conversion of unmethylated cytosine to uracil, while methylated cytosine [both $5 \mathrm{mC}$ and $5 \mathrm{hmC}$ ] remains unchanged. This change can be detected using a variety of methods, including PCR amplification followed by DNA sequencing [55,56]. Methylation-specific PCR [MSP] [57] combines the bisulfite conversion with PCR which reduces the incidences of false positive results due to the incomplete enzymatic digestion and also eliminates the requirement of recognition site in the gene area of interest. COBRA [Combined Bisulfite Restriction Analysis] is a quantitative and sensitive DNA methylation technique to determine the level of DNA methylation in the gene specific loci in small amount of genomic DNA [58]. Methylation-sensitive single nucleotide primer extension [Ms$\mathrm{SNuPE}$ ] is also a modification of the MSP that can be used for rapid quantitation of methylation at individual CpGs [59,60] MCA-MSP follow same principle as that of the MSP whereas MCA-Meth makes use of single sets of primers and is not specific for any methylated or unmethylated region of the DNA. These two techniques provide several advantages over the MSP and other methylation techniques. An additional advantage of MCA-Meth over MCA-MSP is that amplification of unmethylated and methylated promoter can be carried out in a single tube unlike MCP-MSP and thus requires short analysis time, avoids the requirement of gel for documentation, less quantity of DNA, easier to handle and less chances of contamination. However, there are some limitations to MCA-Meth for e.g. in a heterogeneous sequence methylation status of the MSP primers may give unclear results and thus need a second evaluation using MSP, bisulfate sequencing or MCA-MSP. Methylation-specific ligation detection reaction [msLDR] is a sensitive approach for multiplex gene-specific methylation analysis and makes use of ligation-based PCR in combination with TaqMan based-detection and universal reporter probes readouts. Authors have employed this method for analysis of distinct methylation pattern in different genes/loci from 8 different colorectal cancer 
cells in parallel. This method is non-laborious and follows a simple work flow and is expected to be used as a potential diagnostic tool in future [61]. Another recently reported technique-methylation specific electrophoresis [MSE] is the modification of bisulfite-DGGE [denaturing gradient gel electrophoresis] and uses nested PCR approach. This method decrease the amount of DNA required and lowest detection limit for detecting the difference in methylation status is $<0.1 \%$ and minimum detectable amount of DNA is $20 \mathrm{pg}$. Therefore this method can be quite useful for detecting methylation status of region of interest when the small amount of DNA extracted [62]. Methylation specific quantum dot fluorescence resonance energy transfer [MS-qFRET] [63, 64] makes use of forward and reverse primers tagged with biotin and fluorophores respectively. This method is highly sensitive [ $15 \mathrm{pg}$ can be detected], has high resolution which enables one step analysis of multiple genes for the methylation status. Therefore this method has potential application for high-throughput screening. Another modified version [65] of the above process makes use of FRET, methylation sensitive restriction enzymes and an optical amplifier-cationic conjugated polymer. This procedure is simple and avoids the use of labelled primers. Another technique called Methylight [66] is a sodium-bisulfite-dependent, fluorescence-based, real-time PCR method which sensitively detects and quantifies the level DNA methylation. This method makes use of three DNA florescent labelled oligonucleotides [forward, reverse and interpositioned probe] that hybridize in and around the specific methylated region of interest. This method allows a high degree of specificity, sensitivity, and flexibility in methylation detection $[67,68]$.

\section{DEGENERATIVE DISEASES AND EPIGENETIC THERAPY}

There is increasing evidence that epigenetic changes play a critical role in the development of certain human diseases. Cancer, neurodegenerative diseases and aging are well reviewed in literature. In this review we have summarised various epigenetic mechanisms reported recently in diseases like Rheumatoid Arthritis, Asthma, obesity and Alzheimer's disease.

\subsection{Rheumatoid Arthritis}

The Rheumatoid arthritis [RA] is an autoimmune disease characterized by a chronic inflammation of joints mainly affecting synovial joints. Exact etiology of disease is unknown. RA is complex disease governed by various genetic as well as environmental determinants. Cytokines like IL-10 play role in differentiation of T cells into Th1 and Th2. Epigenetic regulation of cytokines are considered as one of the factor associated with inflammatory response. Fu LH et al. have observed promoter methylation in IL-10 is associated with the chromatin remodelling in differentiated Th1 and Th2 cells [69]. It has also been shown that proximal upstream $\mathrm{CpG}$ motif at -145 in IL-10 promoter was hypomethylated in RA patient and was also associated with high levels of IL-10 mRNA and serum levels. Same study also demonstrated increase in binding of transcription factor CREB (cAMP response element-binding) to IL-10 promoter [70]. In a study to determine DNA methylation of IL-6 promoter region in RA patients, Christopher Nile and group compared the methylation status in IL-6 promoter in RA patients and healthy controls. It was reported that upstream motif $-1099 \mathrm{C}$ was hypomethylated in patients than controls. The study suggested that low methylation of $-1099 \mathrm{C}$ site of IL-6 cytokine may increase risk of developing RA [70]. Similarly Ishida et al have demonstrated correlation between lower methylation levels of $\mathrm{CpG}$ motif at -74 bp in IL-6 promoter and increase in serum IL-6 levels in RA patients [71]. Above studies not only suggest the role of IL-10 and IL- 6 in pathogenesis of RA but also provide evidence of epigenetic regulation of these genes in RA.

\subsection{Asthma}

Asthma is a chronic pulmonary disorder of the airways, which involves several inflammatory cells and multiple mediators that result in characteristic pathophysiological changes leading to reversible airway obstruction. IFN- $\gamma$ gene and IL-4 gene are critical modulators of Th1/Th2 balance and play a vital role in pathogenesis of asthma $[72,73]$. Demethylation at the site of proximate promoter and conserved intronic regulatory element [CIRE] in the first intron of the proallergic IL-4 gene and hyper methylation of sites in the counter regulatory INF- $\gamma$ promoter results in greater IL-4 production and differentiation of Th2 cells [74-79]. Eosinophils play a major role in asthma along with eotaxin and IL-5. Use of lentivirus delivered short hairpin RNA suppresses the expression of IL-5 inhibiting the inflammation of airway [80]. IL-13 released by $\mathrm{Th} 2$ regulates the expression of arginase $\mathrm{I}$ in a STAT-6 dependent manner. Using RNA interference, Yang $\mathrm{M}$ et al. have demonstrated that loss of arginase I in the lung reduces the IL-13 induced AHR [81]. Recent studies showed that genes such as Protocadherin-20 [82], Arachidonate 12-lipoxygenase [83], iNOS [Nitric oxide synthase] and IL-6 [84] are differentially methylated in asthmatics and this increases the hope of using DNA methylation regulated genes as possible biomarker or targets for drug interventions.

\subsection{Obesity}

Obesity is a disorder arising due to disequilibrium between individual's dietary intake as well as energy ex- 
penditure. Evidence has supported the role of genetic determinants in predisposing individual to obesity. Environmental as well as genetic determinants interact with each other to develop obesity phenotype. Epigenetic contribution is largely unknown, however few studies in this area has shed some light. Noer et al. have studied the pattern of $\mathrm{CpG}$ methylation of adipogenic promoters leptin (LEP), peroxisome proliferator-activated receptor gamma 2 (PPAR $\gamma 2$ ), fatty acid-binding protein 4 (FABP 4), and lipoproteinlipase (LPL) and nonadipogenic myogenin (MYOG), CD31, and GAPDH in adipose stem cells (ASCs). The adipogeneic loci studied were hypomethylated in undifferentiated cultured ASCs as well as in freshly isolated uncultured ASCs unlike nonadipogenic loci. Interestingly no correlation was observed between DNA methylation and gene expression at any loci except methylation at $\mathrm{CpG}$ motif 21 in LEP promoter and down regulation of LEP. Thus it was concluded that DNA methylation may not be the determinant of expression potential [85]. Melanin-concentrating hormone receptor 1 (MCHR1) plays an important role in regulation of energy homeostasis, food intake and body weight. A negative effect of MCHR1 protein levels and diet induced obesity has been demonstrated in animal models. Recently it has been reported that transcription of MCHR 1 is not only epigenetically regulated but DNA methylation at MCHR1 is associated with age and is allele specific [86].Studies focusing on epigenomics using high through put techniques are necessary to identify epigenetic modifications controlling genes that regulate energy balance, study epigenetic mosaicism, and identify epigenetic biomarkers which can be used commercially.

\subsection{Alzheimer's Disease}

Alzheimer's disease $[\mathrm{AD}]$ is one of the leading neurodegenerative disorders evident clinically at older age. It arises due to protein misfolding of amyloid beta $[\mathrm{A} \beta]$ peptide forming plaques and an abundance of microglia, astrocytes, neurofibrillary tangles. Amyloid $\beta$ is a fragment from a larger protein called amyloid precursor protein [APP], which is a trans membrane protein and critical to neuron growth, survival and post injury repair. APP is broken down into $\mathrm{A} \beta$ by an enzyme $\beta$ amyloid precursor protein converting enzyme [BACE]. AD occurs rarely as early onset form of $\mathrm{AD}$ [EOAD] than late onset form of $\mathrm{AD}$ [LOAD]. Wang et al. have demonstrated DNA methylation pattern in 12 susceptibility loci in brain samples and lymphocytes in LOAD patients. The reversible mechanism of DNA methylation modifies genome function and chromosomal stability through the addition of methyl groups to cytosine located in $\mathrm{CpG}$ dinucleotides to form 5 methylcytosine $[5 \mathrm{mC}][87,88]$. Methylation status of repetitive elements [i.e. Alu, LINE-
1 and SAT- $\alpha$ ] is a major contributor of global DNA methylation patterns studied in various diseases. The study of role of methylation of repetitive elements in blood of AD patients revealed LINE-1 methylation was increased in $\mathrm{AD}$ patients compared with healthy volunteers [89]. Among the studied genes, APOE and TFAM promoters were significantly different with small change in methylation levels within controls and patients. Age dependent epigenetic drift was also seen in MTHFR [methylenetetrahydrofolate reductase] which is a key enzyme regulating with increase in methylation of $\mathrm{CpG}$ islands in $\mathrm{AD}$ patients as compared to controls with age [90]. Herbert et al. have investigated miRNA expression profile in sporadic AD cases. miRNA profile showed 13 significantly expressed out of which 7 had binding sites in 3'UTR of BACE1. The study reported increase in expression of $B A C E 1$ in sporadic $\mathrm{AD}$ as compared to controls. Loss in regulation of miRNA29a/b-1 resulted in increase in expression of $B A C E 1$ and thus $\mathrm{A} \beta$ formation [91]. End-stage in Alzheimer's disease involves drastic modifications in neuronal molecular and cellular processes; a little has been explored about the dynamics of these modifications. Till date little evidence suggests a role of epigenetic modifications in neurodegenerative disorders like $\mathrm{AD}$, but there still is much scope to elucidate further. Studying epigenetic modifications will help to study role of environment in progression of disease, explore pathogenesis and to design newer therapeutic interventions for $\mathrm{AD}$.

\section{EPIGENETIC THERAPY}

Development in genetics and genomics are not only confined to basic understanding about etiology of disease, but also to develop newer drug targets and to improvise the existing ones. Most of these drugs work as inhibitors of DNMTs or HDACs. 5-azacytidine [5 azaC] and 5-aza2 'deoxycytidine [5 azaDC] are the known inhibitors of DNMTs which act by inducing DNA hypomethylation and thus upregulating genes. Currently a cytosine analog, 5-aza-2'deoxycytidine [decitabine] targeting the epigenetic pathway is under clinical trial. Treatment of NIH/ $3 \mathrm{~T} 3$ cell culture with $5 \mathrm{azaC}$ resulted in increase in expression of PPAR $\gamma$ on demethylation of promoter. Increase in $\operatorname{PPAR} \gamma$ can thus reverse the process of destruction of normal functionality of adipocytes [92]. A recent study reported that use of valproic acid [VPA] inhibits transcription of adiponectin in adipocytes via down regulation of $\mathrm{C} / \mathrm{EBP} \alpha$ transcription factor and thus responsible for inducing obese stateVPA is used in treatment of psychotic disorders and obesity is a known side effect of the treatment. VPA increases acetylation of C/EBP $\alpha$ and thus it cannot bind to specific DNA sequence and that might inhibit further expression of adiponectin [93]. In brain disorders like alzheimers me- 
mory loss is a major symptom. A study reported that targeting HDAC class I might improve memory deficit. Injecting HDAC inhibitors, sodium valproate and sodium butyrate, in transgenic mice revealed complete improvement in memory deficit and memory was found to be stable for next two weeks. Studies have shown that histone deacetylases act as neuroprotectors by enhancing synaptic plasticity in Alzheimer's disease [94]. Thus HDAC inhibitors can be used in treating disease state but further studies are required to validate these findings $[95,96]$.

MicroRNAs [miRNAs] play a pivotal role in regulation of gene expression in inflammatory response. They are expressed mostly in tissue specific or developmental stage dependant manner. Nagata et al. injected miRNA15a along with FAM-atelocollagen complex in autoantibody induced male DBA/1J mice. The study reveals that on injection of miRNA15a, apoptosis was successfully induced in RA synovium and miRNA15a can be useful agent in epigenetic therapy [97]. In vivo transfection of small interfering RNA [siRNA] targeting $T N F-\alpha, I L-1$ beta, IL-6 and receptor activator of NF-kappaB ligand $[R A N K L]$ in collagen induced arthritis (CIA) in rats, resulted in effective treatment. Although the study was done on CIA the findings suggest that, transfection of siRNA can be an important strategy to treat diseases by silencing genes using specific siRNAs [98]. In Alzheimer brain, miRNA146a was found to be sensitive to $\mathrm{NF} \kappa \mathrm{B}$ signalling like most of inflammatory response. miRNA 146a was upregulated in stress induced cells and further it represses complement factor $\mathrm{H}[\mathrm{CHF}]$. Thus developing anti-miRNA strategies against specific miRNA might serve as efficient epigenetic therapy [99]. Recent study shows that S-adenosyl L-methionine [SAM] is a universal methyl group donor which participates in transmethylation reactions. It has an important role in the synthesis of neuromediators and melatonin and mechanisms of epigenetic regulation. SAM has proved to act as an epigenetic treatment in rheumatoid arthritis [RA] and various other diseases [100].

Although these epigenetic therapies are promising and are gaining importance, very few of these drugs or therapies have passed clinical trials. Designing a specific drug for a given target is a major challenge faced by researchers. To avoid issues like non specificity Feinberg has suggested targeting biochemical pathways which are epigenetically modified in a disease by conventional medicine. With more input from ongoing research and not to forget the Human epigenome project will help in solving current issues in designing of epigenetic therapies.

\section{ACKNOWLEDGEMENTS}

We thank Office of Principal Scientific Advisors, Goverment of India for financial support.

\section{REFERENCES}

[1] Huber, L.C., Stanczyk, J., Jüngel, A., Gay, S. (2007) Epigenetics in inflammatory rheumatic diseases. Arthritis \& Rheumatism, 56, 3523-3531. doi:10.1002/art.22948

[2] Felsenfeld, G. (2007) A brief history of epigenetics. In: Allis, C.D., Jenuwein, T., Reinberg, D., Caparros, M.L., Eds. Epigenetics, Cold Spring Harbor Laboratory Press, New York, 15-22.

[3] Ballestar, E., Esteller, M. and Richardson, B.C. (2006) The epigenetic face of systemic lupus erythematosus. The Journal of Immunology, 176, 7143-7147.

[4] Klose, R.J. and Bird, A.P. (2006) Genomic DNA methyllation: The mark and its mediators. Trends in Biochemical Sciences, 31, 89-97. doi:10.1016/j.tibs.2005.12.008

[5] Ooi, S.K. and Bestor, T.H. (2008) The colorful history of active DNA demethylation. Cell, 133, 1145-1148. doi:10.1016/j.cell.2008.06.009

[6] Goll, M.G. and Bestor, T.H. (2005) Eukaryotic cytosine methyltransferases. Annual Review of Biochemistry, 74, 481514. doi:10.1146/annurev.biochem.74.010904.153721

[7] Shirohzu, H., Kubota, T., Kumazawa, A., Sado, T., Chijiwa, T., Inagaki, K., Suetake, I., Tajima, S., Wakui, K., Miki, Y., Hayashi, M., Fukushima, Y. and Sasaki, H. (2002) Three novel DNMT3D mutations in Japanese patients with ICF syndrome. American Journal of Medical Genetics, 112, 31-37. doi:10.1002/ajmg.10658

[8] Brenner, C., Deplus, R., Didelot, C., Loriot, A., Viré, E., De Smet, C., Gutierrez, A., Danovi, D., Bernard, D., Boon, T., Pelicci, P.G., Amati, B., Kouzarides, T., de Launoit, Y., Di Croce, L. and Fuks, F. (2005) Myc represses transcripttion through recruitment of DNA methyltransferase corepressor. The EMBO Journal, 24, 336-346. doi:10.1038/sj.emboj.7600509

[9] Kangaspeska, S., Stride, B., Métivier, R., PolycarpouSchwarz, M., Ibberson, D., Carmouche, R.P., Benes, V., Gannon, F. and Reid, G. (2008) Transient cyclical methylation of promoter DNA. Nature, 452, 112-115. doi: $10.1038 /$ nature 06640

[10] Métivier, R., Gallais, R., Tiffoche, C., Le Péron, C., Jurkowska, R.Z., Carmouche, R.P., Ibberson, D., Barath, P., Demay, F., Reid, G., Benes, V., Jeltsch, A., Gannon, F. and Salbert, G. (2008) Cyclical DNA methylation of a transcriptionally active promoter. Nature, 452, 45-50. doi: $10.1038 /$ nature 06544

[11] Ooi, S.K. and Bestor, T.H. (2008) The colorful history of active DNA demethylation. Cell, 133, 1145-1148. doi:10.1016/j.cell.2008.06.009

[12] Luger, K., Mader, A.W., Richmond, R., Sargent, D.F. and Richmond, T.J. (1997) Crystal structure of the nucleosome core particle at 2.8 a resolution. Nature, 389, 251260. doi: $10.1038 / 38444$

[13] Roth, S.Y., Denu, J.M. and Allis, C.D. (2001) Histone acetyltransferases. Annual Review of Biochemistry, 70, 81-120. doi:10.1146/annurev.biochem.70.1.81

[14] Grant, P.A. and Berger, S.L. (1999) Histone acetyltrans- 
ferase complexes. Seminars in Cell \& Developmental Biology, 10, 169-177. doi:10.1006/scdb.1999.0298

[15] Ekwall, K., Olsson, T., Turner, B.M., Cranston, G. and Allshire, R.C. (1997) Transient inhibition of histone deacetylation alters the structural and functional imprint at fission yeast centromeres. Cell, 91, 1021-1032. doi:10.1016/S0092-8674(00)80492-4

[16] Thomson, S., Mahadevan, L.C. and Clayton, A.L. (1999) MAP kinase-mediated signalling to nucleosomes and immediate-early gene induction. Seminars in Cell \& Developmental Biology, 10, 205-214. doi:10.1006/scdb.1999.0302

[17] Downs, J.A., Lowndes, N.F. and Jackson, S.P. (2000) A role for Saccharomyces cerevisiae histone H2A in DNA repair. Nature, 408, 1001-1004. doi:10.1038/35050000

[18] Rogakou, E.P., Boon, C., Redon, C. and Bonner, W.M. (1999) Megabase chromatin domains involved in DNA double-strand breaks in vivo. The Journal of Cell Biology, 146, 905-916. doi:10.1083/jcb.146.5.905

[19] Lee, D.Y., Teyssier, C., Strahl, B.D. and Stallcup, M.R. (2005) Role of protein methylation in regulation of transcription. Endocrine Reviews, 26, 147-170. doi:10.1210/er.2004-0008

[20] Lachner, M., Sengupta, R., Schotta, G. and Jenuwein, T. (2004) Trilogies of histone lysine methylation as epigenetic landmarks of the eukaryotic genome. Cold Spring Harbor Symposia on Quantitative Biology, 69, 209-218. doi:10.1101/sqb.2004.69.209

[21] Lachner, M., O'Carroll, D., Rea, S., Mechtler, K. and Jenuwein, T. (2001) Methylation of histone H3 lysine 9 creates a binding site for HP1 proteins. Nature, 1, 410, 116-120. doi:10.1038/35065132

[22] Shi, Y., Lan, F., Matson, C., Mulligan, P., Whetstine, J.R., Cole, P.A., Casero, R.A. and Shi, Y. (2004) Histone demethylation mediated by the nuclear amine oxidase homolog LSD1. Cell, 119, 941-953. doi:10.1016/j.cell.2004.12.012

[23] Tsukada, Y., Fang, J., Erdjument-Bromage, H., Warren, M.E., Borchers, C.H., Tempst, P. and Zhang, Y. (2006) Histone demethylation by a family of JmjC domaincontaining proteins. Nature, 439, 811-816. doi:10.1038/nature 04433

[24] Nakahara, K. and Carthew, R.W. (2004) Expanding roles for miRNAs and siRNAs in cell regulation. Current Opinion in Cell Biology, 16, 127-133. doi:10.1016/j.ceb.2004.02.006

[25] Hannon, G.J. (2002) RNA interference. Nature, 418, 244251. doi: $10.1038 / 418244 \mathrm{a}$

[26] Volpe, T.A., Kidner, C., Hall, I.M., Teng, G., Grewal, S.I. and Martienssen, R.A. (2002) Regulation of heterochromatic silencing and histone H3 lysine- 9 methylation by RNAi. Science, 297, 1833-1837. doi:10.1126/science.1074973

[27] Hayashizaki, Y., Hirotsune, S., Okazaki, Y., Hatada, I., Shibata, H., Kawai, J., Hirose, K., Watanabe, S., Fushiki, S., Wada, S., et al. (1993) Restriction landmark genomic scanning method and its various applications. Electrophoresis, 14, 251-258. doi:10.1002/elps.1150140145
[28] Frigola, J., Ribas, M., Risques, R.A. and Peinado, M.A. (2002) Methylome profiling of cancer cells by amplifycation of inter-methylated sites [AIMS]. Nucleic Acids Research, 30, e28. doi:10.1093/nar/30.7.e28

[29] Huang, T.H., Perry, M.R. and Laux, D.E. (1999) Methylation profiling of $\mathrm{CpG}$ islands in human breast cancer cells. Human Molecular Genetics, 8, 459-470. doi: $10.1093 / \mathrm{hmg} / 8.3 .459$

[30] Stewart, F.J., Panne, D., Bickle, T.A. and Raleigh, E.A. (2000) Methyl-specific DNA binding by McrBC, a modification-dependent restriction enzyme. Journal of Molecular Biology, 298, 611-622. doi:10.1006/jmbi.2000.3697

[31] Ordway, J.M., Bedell, J.A., Citek, R.W., Nunberg, A., Garrido, A., Kendall, R., Stevens, J.R., Cao, D., Doerge, R.W., Korshunova, Y., Holemon, H., McPherson, J.D., Lakey, N., Leon, J., Martienssen, R.A. and Jeddeloh, J.A. (2006) Comprehensive DNA methylation profiling in a human cancer genome identifies novel epigenetic targets. Carcinogenesis, 27, 2409-2423. doi:10.1093/carcin/bgl161

[32] Ordway, J.M., Budiman, M.A., Korshunova, Y., Maloney, R.K., Bedell, J.A., Citek, R.W., Bacher, B., Peterson, S., Rohlfing, T., Hall, J., Brown, R., Lakey, N., Doerge, R.W., Martienssen, R.A., Leon, J., McPherson, J.D. and Jeddeloh, J.A. (2007) Identification of novel high-frequency DNA methylation changes in breast cancer. PLoS One, 2, e1314. doi:10.1371/journal.pone.0001314

[33] Khulan, B., Thompson, R.F., Ye, K., Fazzari, M.J., Suzuki, M., Stasiek, E., Figueroa, M.E., Glass, J.L., Chen, Q., Montagna, C., Hatchwell, E., Selzer, R.R., Richmond, T.A., Green, R.D., Melnick, A. and Greally, J.M. (2006) Comparative isoschizomer profiling of cytosine methylation: The HELP assay. Genome Research, 16, 1046-1055. doi:10.1101/gr.5273806

[34] Oda, M., Glass, J.L., Thompson, R.F., Mo, Y., Olivier, E.N., Figueroa, M.E., Selzer, R.R., Richmond, T.A., Zhang, X., Dannenberg, L., Green, R.D., Melnick, A., Hatchwell, E., Bouhassira, E.E., Verma, A., Suzuki, M. and Greally, J.M. (2009) High-resolution genome-wide cytosine methylation profiling with simultaneous copy number analysis and optimization for limited cell numbers. Nucleic Acids Research, 37, 3829-3839. doi:10.1093/nar/gkp260

[35] Ibrahim, A.E., Thorne, N.P., Baird, K., Barbosa-Morais, N.L., Tavaré, S., Collins, V.P., Wyllie, A.H., Arends, M.J. and Brenton, J.D. (2006) MMASS: An optimized arraybased method for assessing $\mathrm{CpG}$ island methylation. $\mathrm{Nu}$ cleic Acids Research, 34, e136. doi:10.1093/nar/gk1551

[36] Rollins, R.A., Haghighi, F., Edwards, J.R., Das, R., Zhang, M.Q., Ju, J. and Bestor, T.H. (2006) Large-scale structure of genomic methylation patterns. Genome Research, 16, 157-163. doi:10.1101/gr.4362006

[37] Schumacher, A., Kapranov, P., Kaminsky, Z., Flanagan, J., Assadzadeh, A., Yau, P., Virtanen, C., Winegarden, N., Cheng, J., Gingeras, T. and Petronis, A. (2006) Microarraybased DNA methylation profiling: Technology and applications. Nucleic Acids Research, 3, 528-542. doi:10.1093/nar/gkj461 
[38] Mohn, F., Weber, M., Schübeler, D. and Roloff, T.C. (2009) Methylated DNA immunoprecipitation [MeDIP]. Methods in Molecular Biology, 507, 55-64. doi:10.1007/978-1-59745-522-0 5

[39] Weber, M., Davies, J.J., Wittig, D., Oakeley, E.J., Haase, M., Lam, W.L. and Schübeler, D. (2005) Chromosomewide and promoter-specific analyses identify sites of differential DNA methylation in normal and transformed human cells. Nature Genetics, 37, 853-862. doi:10.1038/ng1598

[40] Weber, M., Hellmann, I., Stadler, M.B., Ramos, L., Pääbo, S., Rebhan, M. and Schübeler, D. (2007) Distribution, silencing potential and evolutionary impact of promoter DNA methylation in the human genome. Nature Genetics, 39, 457-466. doi:10.1038/ng1990

[41] Rauch, T.A. and Pfeifer, G.P. (2009) The MIRA method for DNA methylation analysis. Methods in Molecular Biology, 507, 65-75. doi:10.1007/978-1-59745-522-0 6

[42] Statham, A.L. et al. (2012) Bisulphite-sequencing of chromatin immunoprecipitated DNA [BisChIP-seq] directly informs methylation status of histone-modified DNA. Genome Research, 22, 1120-1127. doi:10.1101/gr.132076.111

[43] Irizarry, R.A., Ladd-Acosta, C., Carvalho, B., Wu, H., Brandenburg, S.A., Jeddeloh, J.A., Wen, B. and Feinberg, A.P. (2008) Comprehensive high-throughput arrays for relative methylation [CHARM]. Genome Research, 18, 80-90. doi:10.1101/gr.7301508

[44] Kageyama, S., Shinmura, K., Yamamoto, H., Goto, M., Suzuki, K., Tanioka, F., Tsuneyoshi, T. and Sugimura, H. (2008) Fluorescence-labeled methylation-sensitive amplified fragment length polymorphism [FL-MS-AFLP] analysis for quantitative determination of DNA methylation and demethylation status. Japanese Journal of Clinical Oncology, 38, 317-322. doi:10.1093/jico/hyn021

[45] Karimi, M. et al. (2006) LUMA [LUminometric Methylation Assay]_A high throughput method to the analysis of genomic DNA methylation. Experimental Cell Research, 312, 1989-1995. doi:10.1016/j.yexcr.2006.03.006

[46] Hatada, I., Fukasawa, M., Kimura, M., Morita, S., Yamada, K., Yoshikawa, T., Yamanaka, S., Endo, C., Sakurada, A., Sato, M., Kondo, T., Horii, A., Ushijima, T. and Sasaki, H. (2006) Genome-wide profiling of promoter methylation in human. Oncogene, 25, 3059-3064. doi:10.1038/sj.onc.1209331

[47] Falck, E. et al. (2012) Genome-wide DNA methylation level analysis by micellar electrokinetic chromatography and laser-induced fluorescence detection after treatment of cell lines with azacytidine and antifolates. Analytical Biochemistry, 421, 439-445. doi:10.1016/j.ab.2011.09.027

[48] Esteller, M., Fraga, M.F., Guo, M., Garcia-Foncillas, J., Hedenfalk, I., Godwin, A.K., Trojan, J., Vaurs-Barrière, C., Bignon, Y.J., Ramus, S., Benitez, J., Caldes, T., Akiyama, Y., Yuasa, Y., Launonen, V., Canal, M.J., Rodriguez, R., Capella, G., Peinado, M.A., Borg, A., Aaltonen, L.A., Ponder, B.A., Baylin, S.B. and Herman, J.G. (2001) DNA methylation patterns in hereditary human cancers mimic sporadic tumorigenesis. Human Molecular Genetics, 10, 3001-3007. doi:10.1093/hmg/10.26.3001

[49] Ramsahoye, B.H. (2002) Measurement of genome wide DNA methylation by reversed-phase high-performance liquid chromatography. Methods, 27, 156-161. doi:10.1016/S1046-2023(02)00069-5

[50] Stach, D., Schmitz, O.J., Stilgenbauer, S., Benner, A., Döhner, H., Wiessler, M. and Lyko, F. (2003) Capillary electrophoretic analysis of genomic DNA methylation levels. Nucleic Acids Research, 31, e2. doi:10.1093/nar/gng002

[51] Song, L., James, S.R., Kazim, L., Karpf and A.R. (2005) Specific method for the determination of genomic DNA methylation by liquid chromatography-electrospray ionization tandem mass spectrometry. Analytical Chemistry, 77, 504-510. doi:10.1021/ac0489420

[52] Armstrong, K.M., Bermingham, E.N., Bassett, S.A., Treloar, B.P., Roy, N.C. and Barnett, M.P. (1994) Global DNA methylation measurement by HPLC using low amounts of DNA. Biotechnology Journal, 6, 113-117. doi:10.1002/biot.201000267

[53] Kurita, R. et al. (2012) Determination of DNA methylation using electrochemiluminescence with surface accumulable coreactant. Analytical Chemistry, 84, 1799-1803. doi:10.1021/ac202692f

[54] Ge, C. et al. (2012) A simple colorimetric detection of DNA methylation. The Analyst, 137, 2032-2035. doi:10.1039/c2an35043b

[55] Clark, S.J., Harrison, J., Paul, C.L. and Frommer, M. (1994) High sensitivity mapping of methylated cytosines. Nucleic Acids Research, 22, 2990-2997. doi:10.1093/nar/22.15.2990

[56] Herman, J.G., Graff, J.R., Myöhänen, S., Nelkin, B.D. and Baylin, S.B. (1996) Methylation-specific PCR: A novel PCR assay for methylation status of $\mathrm{CpG}$ islands. Proceedings of the National Academy of Sciences of the United States of America, 93, 9821-9826. doi:10.1073/pnas.93.18.9821

[57] Xiong, Z. and Laird, P.W. (1997) COBRA: A sensitive and quantitative DNA methylation assay. Nucleic Acids Research, 25, 2532-2534. doi:10.1093/nar/25.12.2532

[58] Gonzalgo, M.L. and Jones, P.A. (1997) Rapid quantitation fo methylation differences at specific sites using methylation-sensitive single nucleotide primer extension [Ms-SNuPE]. Nucleic Acids Research, 25, 2529-2531. doi:10.1093/nar/25.12.2529

[59] Lorente, A., Mueller, W., Urdangarín, E., Lázcoz, P., von Deimling, A. and Castresana, J.S. (2008) Detection of methyllation in promoter sequences by melting curve analysisbased semiquantitative real time PCR. BMC Cancer, 8, 61. doi:10.1186/1471-2407-8-61

[60] Bormann, F., et al. (2012) Methylation-specific ligation detection reaction [msLDR]: A new approach for multiplex evaluation of methylation patterns. Molecular Genetics and Genomics, 286, 279-291. doi:10.1007/s00438-011-0645-9

[61] Yokoyama, S., et al. (2012) The application of methylation specific electrophoresis [MSE] to DNA methylation 
analysis of the $5, \mathrm{CpG}$ island of mucin in cancer cells. BMC Cancer, 12, 67. doi:10.1186/1471-2407-12-67

[62] Bailey, V.J., Easwaran, H., Zhang, Y., Griffiths, E., Belinsky, S.A., Herman, J.G., Baylin, S.B., Carraway, H.E. and Wang, T.H. (2009) MS-qFRET: A quantum dot-based method for analysis of DNA methylation. Genome Research, 19, 1455-1461. doi:10.1101/gr.088831.108

[63] Bailey, V.J., Keeley, B.P., Razavi, C.R., Griffiths, E., Carraway, H.E. and Wang, T.H. (2010) DNA methylation detection using MS-qFRET, a quantum dot-based nanoassay. Methods, 52, 237-241. doi:10.1016/j.ymeth.2010.03.007

[64] Feng, F., Liu, L. and Wang, S. (2010) Fluorescent conjugated polymer-based FRET technique for detection of DNA methylation of cancer cells. Nature Protocols, 5, 1255-1264. doi:10.1038/nprot.2010.79

[65] Campan, M., Weisenberger, D.J., Trinh, B. and Laird, P.W. (2009) MethyLight. Methods in Molecular Biology, 507, 325-337. doi:10.1007/978-1-59745-522-0 23

[66] Trinh, B.N., Long, T.I. and Laird, P.W. (2001) DNA methylation analysis by MethyLight technology. Methods, 25, 456-462. doi:10.1006/meth.2001.1268

[67] Eads, C.A., Danenberg, K.D., Kawakami, K., Saltz, L.B., Blake, C., Shibata, D., Danenberg, P.V. and Laird, P.W. (2000) MethyLight: A high-throughput assay to measure DNA methylation. Nucleic Acids Research, 28, e32. doi:10.1093/nar/28.8.e32

[68] Deighton, C. and Criswell, L.A. (2006) Recent advances in the genetics of rheumatoid arthritis. Current Rheumatology Reports, 8, 394-400. doi:10.1007/s11926-006-0071-x

[69] Fu, L.H., Cong, B., Zhen, Y.F., Li, S.J., Ma, C.L. Ni, Z.Y., Zhang, G.Z., Zuo, M. and Yao, Y.X. (2007) Methylation status of the IL-10 gene promoter in the peripheral blood mononuclear cells of rheumatoid arthritis patients. Yi Chuan, 29, 1357-1361. doi:10.1360/yc-007-1357

[70] Nile, C., Read, R., Akil, M., Duff, G. and Wilson, A. (2008) Methylation status of a single CpG site in the IL6 promoter is related to IL6 messenger RNA levels and rheumatoid arthritis. Arthritis \& Rheumatism, 58, 26862693. doi:10.1002/art.23758

[71] Ishida, K., Kobayashi, T., Ito, S., Komatsu, Y., Yokoyama, T., Okada, M., Abe, A., Murasawa, A. and Yoshie, H. (2011) Interleukin 6 gene promoter methylation in rheumatoid arthritis and chronic periodontitis. Journal of Periodontology, 83, 917-925. doi:10.1902/jop.2011.110356

[72] Kwon, N.H., Kim, J.S., Lee, J.Y., Oh, M.J. and Choi, D.C. (2008) DNA methylation and the expression of IL-4 and IFN-gamma promoter genes in patients with bronchial asthma. Journal of Clinical Immunology, 28, 139-146. doi:10.1007/s10875-007-9148-1

[73] Miller, R.L. and Ho, S.M. (2008) Environmental epigenetics and asthma: Current concepts and call for studies. American Journal of Respiratory and Critical Care Medicine, 177, 567-753. doi:10.1164/rccm.200710-1511PP
[74] Lee, D.U., Agarwal, S. and Rao, A. (2002) Th2 lineage commitment and efficient IL-4 production involves extended demethylation of the IL-4 gene. Immunity, 16, 649-660. doi:10.1016/S1074-7613(02)00314-X

[75] Agarwal, S. and Rao, A. (1998) Modulation of chromatin structure regulates cytokine gene expression during $\mathrm{T}$ cell differentiation. Immunity, 9, 765-775. doi:10.1016/S1074-7613(00)80642-1

[76] Tykocinski, L.O., Hajkova, P., Chang, H.D., Stamm, T., Sözeri, O., Löhning, M., Hu-Li, J., Niesner, U., Kreher, S., Friedrich, B., Pannetier, C., Grütz, G., Walter, J., Paul, W.E. and Radbruch, A. (2005) A critical control element for interleukin-4 memory expression in T helper lymphocytes. The Journal of Biological Chemistry, 280, 2817728185. doi:10.1074/jbc.M502038200

[77] Jones, B. and Chen, J. (2006) Inhibition of IFN-gamma transcription by site-specific methylation during $\mathrm{T}$ helper cell development. The EMBO Journal, 25, 2443-2452. doi:10.1038/sj.emboj.7601148

[78] Brand, S. et al. (2012) DNA methylation of $\mathrm{T}_{\mathrm{H}} 1 / \mathrm{T}_{\mathrm{H}} 2$ cytokine genes affects sensitization and progress of experimental asthma. Journal of Allergy and Clinical Immunology, 129, 1602-1610. doi:10.1016/j.jaci.2011.12.963

[79] Murahidy, A., Ito, M., Adcoc, I.M., Barnes, P.J. and Ito, K. (2005) Reduction of histone deacetylase expression and activity in smoking asthmatics. American Journal of Respiratory and Critical Care Medicine.

[80] Huang, H.Y., Lee, C.C. and Chiang, B.L. (2009) Shorthairpin RNAs against eotaxin or interleukin-5 decrease airway eosinophilia and hyperresponsiveness in murine model of asthma. The Journal of Gene Medicine, 11, 112118.

[81] Yang, M., Rangasamy, D., Matthaei, K.I., Frew, A.J., Zimmmermann, N., Mahalingam, S., Webb, D.C., Tremethick, D.J., Thompson, P.J., Hogan, S.P., Rothenberg, M.E., Cowden, W.B. and Foster, P.S. (2006) Inhibition of arginase I actibity by RNA interference attenuates IL-13 induced airway hyperresponsiveness. The Journal of Immunology, 177, 5595-5603. doi:10.1002/jgm.1285

[82] Sood, A., et al. (2012) Methylated genes in sputum among older smokers with asthma. Chest, 142, 425-431. doi:10.1378/chest.11-2519

[83] Morales, E., et al. (2012) DNA hypomethylation at ALOX12 is associated with persistent wheezing in childhood. American Journal of Respiratory and Critical Care Medicine, 185, 937-943. doi:10.1164/rccm.201105-08700C

[84] Baccarelli, A., et al. (2012) Nasal cell DNA methylation, inflammation, lung function and wheezing in children with asthma. Future Medicine, 4, 91-100.

[85] Noer, A., Sørensen, A.L., Boquest, A.C. and Collas, P. (2006) Stable $\mathrm{CpG}$ hypomethylation of adipogenic promoters in freshly isolated, cultured, and differentiated mesenchymal stem cells from adipose tissue. Molecular Biology of the Cell, 17, 3543-3556. doi:10.1091/mbc.E06-04-0322

[86] Stepanow, S., Reichwald, K., Huse, K., Gausmann, U., Nebel, A., Rosenstiel, P., Wabitsch, M., Fischer-Posovszky, 
P. and Platzer, M. (2011) Allele-specific, age-dependent and BMI-associated DNA methylation of human MCHR1. PLoS One, 6, e17711. doi:10.1371/journal.pone.0017711

[87] Kwok, J.B. (2010) Role of epigenetics in Alzheimer's and Parkinson's disease. Epigenomics, 2, 671-682. doi:10.2217/epi.10.43

[88] Coppieters, N. and Dragunow, M. (2011) Epigenetics in Alzheimer's disease: A focus on DNA modifications. Current Pharmaceutical Design, 17, 3398-3412. doi:10.2174/138161211798072544

[89] Bollati, V., Galimberti, D., Pergoli, L., Dalla Valle, E., Barretta, F., Cortini, F., Scarpini, E., Bertazzi, P.A. and Baccarelli, A. (2011) DNA methylation in repetitive elements and Alzheimer disease. Brain, Behavior, and Immunity, 25, 1078-1083. doi:10.1016/j.bbi.2011.01.017

[90] Wang, S.C., Oelze, B. and Schumacher, A. (2008) Agespecific epigenetic drift in late-onset Alzheimer's disease. PLoS One, 3, e2698. doi:10.1371/journal.pone.0002698

[91] Hébert, S.S., Horré, K., Nicolaï, L., Papadopoulou, A.S., Mandemakers, W., Silahtaroglu, A.N., Kauppinen, S., Delacourte, A. and Strooper, B.D. (2008) Loss of microRNA cluster miR-29a/b-1 in sporadic Alzheimer's disease correlates with increased BACE1/ $\beta$-secretase expression. Proceedings of the National Academy of Sciences of the United States of America, 105, 6415-6420.

[92] Fujiki, K., Kano, F., Shiota, K. and Murata, M. (2009) Expression of the peroxisome proliferator activated receptor $\gamma$ gene is repressed by DNA methylation in visceral adipose tissue of mouse models of diabetes. BMC Biology, 7, 38. doi:10.1186/1741-7007-7-38

[93] Qiao, L., Schaack, J. and Shao, J. (2006) Suppression of adiponectin gene expression by histone deacetylase inhibitor valproic acid. Endocrinology, 147, 865-874. doi:10.1210/en.2005-1030

[94] Xu, K., Dai, X.L., Huang, H.C. and Jiang, Z.F. (2011) Targeting HDACs: A promising therapy for Alzheimer's disease. Oxidative Medicine and Cellular Longevity, 2011, 143269. doi:10.1155/2011/143269

[95] Venkataramani, V., Rossner, C., Iffland, L., Schweyer, S., Tamboli, I.Y., Walter, J., Wirths, O. and Bayer, T.A. (2010) Histone deacetylase inhibitor valproic acid inhibits cancer cell proliferation via down-regulation of the Alzheimer amyloid precursor protein. The Journal of Biological Chemistry, 285, 10678-10689. doi:10.1074/jbc.M109.057836

[96] Gray, S.G. (2011) Epigenetic treatment of neurological disease. Epigenomics, 3, 431-450. doi:10.2217/epi.11.67

[97] Nagata, Y., Nakasa, T., Mochizuki, Y., Ishikawa, M., Miyaki, S., Shibuya, H., Yamasaki, K., Adachi, N., Asahara, H. and Ochi, M. (2009) Induction of apoptosis in the synovium of mice with autoantibody-mediated arthritis by the intraarticular injection of double-stranded MicroRNA-15a. Arthritis \& Rheumatism, 60, 2677-2683. doi:10.1002/art.24762

[98] Inoue, A., Takahashi, K.A., Mazda, O., Arai, Y., Saito, M., Kishida, T., Shin-Ya, M., Morihara, T., Tonomura, H., Sakao, K., et al. (2009) Comparison of anti-rheumatic effects of local RNAi-based therapy in collagen induced arthritis rats using various cytokine genes as molecular targets. Modern Rheumatology, 19, 125-133. doi:10.1007/s10165-008-0131-3

[99] Lukiw, W.J., Zhao, Y. and Cui, J.G. (2008) An NF- $\kappa$ Bsensitive micro RNA-146a-mediated inflammatory circuit in alzheimer disease and in stressed human brain cells. The Journal of Biological Chemistry, 283, 31315-31322. doi:10.1074/jbc.M805371200

[100] Krzystanek, M., Pałasz, A., Krzystanek, E., Krupka-Matuszczyk, I., Wiaderkiewicz, R., Skowronek, R. (2011) Sadenosyl L-methionine in CNS diseases. Psychiatria Polska, 45, 923-931. 